\title{
A BIBLIOTECÁRIA DINAMARQUESA E A NEGOCIAÇÃO CULTURAL: NOVO PARADIGMA PARA A MEDIAÇÃO E APROPRIAÇÃO DA INFORMAÇÃO
}

\author{
EL BIBLIOTECARIO DANÉS Y CULTURAL \\ NEGOCIACIÓN: NUEVO PARADIGMA PARA LA \\ MEDIACIÓN Y PROPIEDAD DE LA INFORMACIÓN
}

Amanda Leal de Oliveira*

\section{RESUMO}

Introdução: Apresenta resultados de tese de doutoramento.

Objetivo: contribuir para a definição e desenvolvimento do conceito de "negociação cultural", compreendido como categoria teorico-metodológica fundamental aos processos de mediação voltados à apropriação da informação.

Metodologia: Foi utilizada metodologia colaborativa, processo de construção científica baseado na interlocução entre saberes e fazeres científicos e "da ação", adotando-se, porém, perspectiva que não reduz ou sobrepõe uns aos outros.

Resultados: Os resultados mostram que, reconhecendo e incorporando a seus conceitos e processos os conflitos provocados pelas divergências e/ou assimetrias existentes entre os diferentes sujeitos, grupos, segmentos, categorias, matrizes socioculturais (leitores/não-leitores, tradição oral/cultura escrita), 0 dispositivo apresentado (biblioteca pública na Dinamarca), diferentemente de outros do mesmo teor, mais que instâncias de controle e/ou de difusão, são instâncias de negociação cultural, envolvendo sujeitos, textos e contextos em processos ativos, complexos e afirmativos de apropriação de informação e cultura, incluída aí - mas não exclusivamente - a cultura escrita.

Conclusões: O conceito de negociação cultural aponta, portanto, para perspectivas novas, tanto em relação à apropriação da cultura escrita, como da cultura em geral. Dá mostras, ao mesmo tempo, de poder contribuir para a redefinição indispensável de práticas e conceitos de mediação da informação e seus paradigmas.

Palavras-chave: Mediação; Negociação cultural; Apropriação; Biblioteca; Cultura escrita.

\footnotetext{
* Doutora em Ciência da Informação (ECA/USP). Pesquisadora do Colaborl (CBD/ECA/USP) email: amanleal@gmail.com
} 


\section{INTRODUÇÃO}

Bilhões de pessoas em todo o mundo, alfabetizadas ou não, estão afetadas pela palavra escrita. Crianças, jovens e adultos, estamos, todos, mergulhados em um mundo onde a escrita pulula e ocupa um papel central na vida política, econômica, cultural e social. Diante de tal quadro, saber ler e escrever, utilizar-se da linguagem escrita, torna-se, cada vez mais, condição indispensável ao pleno desenvolvimento da autonomia e da cidadania, nos mais diferentes contextos.

Dado o alcance, o valor e a função que a escrita ocupa no cotidiano, torna-se difícil imaginar a vida humana sem essa prática. Apesar dessa constatação, segundo relatório da ONU, de 2013 (UNESCO, 2015), são 274 milhões de analfabetos no mundo, sendo que $72 \%$ deles estão em dez países - o Brasil é o oitavo com maior concentração'.

Pesquisas demonstram que o número de analfabetos alcança quase $10 \%$ da população brasileira (cerca de 13 milhões de pessoas) e, mesmo entre aqueles que dominam o código, a grande maioria faz apenas uso parcial da escrita, sem conseguir ler e escrever textos mais amplos²: aproximadamente $25 \%$ da população brasileira é considerada "analfabeta funcional".

Diante desse quadro, é possível afirmar que, no Brasil, a apropriação da escrita não se universalizou. Entre a população analfabeta e a letrada existe um longo percurso a ser construído e, se iniciativas estão em processo há algum tempo, uma política efetiva que integre ações, programas e instituições representações indispensáveis à constituição de uma sociedade que demonstra intimidade com os diferentes usos sociais que a palavra escrita possibilita - é, ainda, uma promessa.

\footnotetext{
${ }^{1}$ O primeiro é a Índia, com cerca de 287 milhões (22\% da população), seguido da China (52 milhões / 3,85\% da população), e o terceiro é o Paquistão, com 49,5 milhões de analfabetos ( $26,7 \%$ de sua população).

2. Segundo o INAF (Indicador Nacional de Alfabetismo Funcional) de 2011, apenas 1 em cada 4 brasileiros com mais de 15 anos consegue ler e compreender plenamente um texto, e $62 \%$ das pessoas com ensino superior e $35 \%$ das pessoas com ensino médio completo são classificadas como plenamente alfabetizadas. (INSTITUTO PAULO MONTENEGRO, 2011).
} 

mediação e apropriação da informação

Quais os caminhos a serem trilhados no sentido de enfrentar essa realidade?

O pesquisador Roger Chartier (1988) afirma que a história é marcada explicitamente por duas concepções do ato de ler: uma que atribui poder absoluto ao texto escrito; outra que considera a irredutível liberdade do leitor. $\mathrm{A}$ antropóloga Michèle Petit, em seu livro Os jovens e a leitura: uma nova perspectiva (2008), também confirma essa compreensão ao descrever o que denominou de "as duas vertentes da leitura"; a primeira marcada por tentativas de imposição dos sentidos do texto aos leitores, e a segunda, por experiências que revelam as transgressões dos leitores no processo de significação - a inevitável "alquimia da recepção". Partiremos da constatação desses dois pesquisadores da leitura para apontar caminhos do que seria então uma "terceira vertente", aquela que afirma e reconhece que a apropriação da escrita se dá na tensão contínua entre demandas dos textos (objetos culturais), dos leitores e dos contextos.

A linguagem escrita está, de fato, intimamente relacionada ao poder e à dominação. Em Uma história da leitura, Alberto Manguel (1996) afirma que o chicote e o livro foram, durante séculos, os principais símbolos daqueles que sabiam e ensinavam a ler. E, ainda hoje, é possível reconhecer como o medo e a submissão continuam atrelados aos processos de participação na cultura escrita.

Por outro lado, como já evidenciavam os pesquisadores anteriormente citados, mesmo onde parece haver controle total sobre o acesso e conteúdo dos textos, os leitores não são totalmente dominados. Nesse sentido, a história da leitura é pródiga em exemplos que evidenciam a liberdade do leitor, pois, no limite, sempre caberão aos sujeitos a apropriação dos textos, a atribuição de seus significados, a alteração de seus sentidos, a interpretação à sua maneira.

Mas, se não é possível controlar de fato o modo como o texto será lido, compreendido, utilizado, interpretado, isso não minimiza, todavia, a grande participação que têm o texto e o contexto nos processos de significação construídos pelo leitor. Pouco avançaremos em nossas políticas de leitura nos contentando em considerar que, tais como "caçadores" (CERTEAU, 1994), os 
leitores viverão a procurar brechas em territórios alheios e a esquivar-se de tentativas concretas e simbólicas de imposição e sobreposição cultural.

Se pensarmos especificamente no Brasil, a leitura e a escrita foram introduzidas no país nos quadros de um projeto de colonização (PERROTTI, PIERUCCINI, 2007): os textos trazidos pelos jesuítas portugueses e difundidos entre a população local eram portadores das verdades a serem apreendidas pelos colonizados, de forma que, ao serem ensinados a identificar palavras, os leitores tinham como única missão assimilar a "verdadeira" cultura; deveriam aprender a decifrar os sinais do texto, cujos sentidos eram dados e acabados pelo colonizador.

Instituições educacionais e culturais, ligadas em geral à Igreja e à Realeza, de comum acordo, difundiram, por longo período, concepções e práticas afinadas com o projeto expansionista português, tomando a escrita como objeto de reprodução e assimilação de conteúdos veiculados e controlados pela ordem cultural hegemônica. A aprendizagem da leitura e da escrita, nesse quadro, acabou atrelada a um projeto de dominação e expropriação cultural que não só exerceu severo controle sobre a produção e circulação da escrita na colônia, como também, de fato, exterminou e perseguiu vozes e culturas dissonantes.

Lévi-Strauss (1996, p. 336), ao escrever sobre sua experiência entre os indígenas Nhambikuara do Brasil, afirma:

Ainda que a escrita não tenha sido suficiente para consolidar o conhecimento, ela foi talvez indispensável para fortalecer a dominação... A luta contra o analfabetismo está em relação com um crescimento da autoridade dos governos sobre os cidadãos. Todos têm que ser capazes de ler, de forma que o governo possa dizer: a ignorância da lei não é desculpa.

Bibliotecas e escolas, em muitos casos, surgiram e seguiram constituídas sobre premissas que deram sustentação a processos de imposição e exclusão cultural e não é casual que Paulo Freire (1981a; 1981b; 1982, 1983) tenha encontrado no Brasil, em meados dos anos de 1950, contexto para formular suas concepções sobre leitura e escrita como um meio de conscientização em face da "domesticação" implícita nas pedagogias da 
leitura, ainda baseadas em concepções mecânicas e mecanicistas da alfabetização e da linguagem em geral.

Freire chamou, assim, a atenção do país, tanto para as possibilidades da escrita, como para as mediações socioculturais a ela historicamente relacionadas. Assim, se ler pode ser caminho para a "conscientização", a liberdade, é possível levantar a hipótese de que a construção de significados com e pela escrita deve ser favorecida por políticas de mediação que promovam encontros, "negociações" entre sujeitos, textos e meios socioculturais marcados por processos dialógicos, criativos e abertos à construção de (novos) conhecimentos, sujeitos e práticas culturais.

Desse modo, tendo em vista a importância capital das mediações socioculturais nos processos de significação (discussão que será apresentada na Seção 2), consideramos imprescindível gerar canais de reflexão e avaliação que apontem caminhos nesse sentido, pois, ainda hoje, não é incomum oscilarem visões marcadas pelas duas vertentes anteriormente apontadas e que alimentam lugares comuns do tipo "quem não lê não pensa", como fez recente pesquisa nacional sobre os índices de leitura no Brasil (INSTITUTO PRÓ-LIVRO, 2011).

Essa afirmação, mais do que revelar preconceitos que estratos sociais letrados exibem ao se referirem àqueles que não aprenderam a ler, evidencia uma concepção de leitura que ainda vigora no país e que necessita ser problematizada e ultrapassada, pois pouco ou nada colabora para o avanço da cultura escrita - e dos leitores. Associada à inteligência, à superioridade da modernidade sobre outros tempos, ao maior desenvolvimento cognitivo e cultural, a leitura passa a ter sua antítese na "não leitura", categoria vinculada automaticamente à tolice, à ignorância, à incultura, ou seja, a critérios de valor abstratos, sem fundamentação no mundo concreto e objetivo, mas que legitimam discriminações e exclusões nascidas da ordem sociocultural, ao mesmo tempo que criam hierarquias entre culturas, base do pensamento etnocêntrico.

Para sustentarmos uma posição acerca da leitura - e da necessidade de sua difusão - baseada em argumentos que valorizam o ato de ler como prática 

mediação e apropriação da informação

cultural superior a todas as outras, precisaríamos ignorar estudos antropológicos, linguísticos e psicológicos que nos demonstram que sujeitos não letrados também apresentam qualidades cognitivas ${ }^{3}$ especiais e relacionadas às demandas e aos quadros culturais em que atuam. Além disso, estaríamos operando em um paradigma evolucionista de cultura, caminho que leva a impasses e inconsistências incapazes de compreender os fenômenos culturais em sua complexidade, diversidade e riqueza.

Mas, ao contrário, se concebermos que "[...] as diferenças entre as formas de pensamento de diversas culturas dizem respeito às maneiras de pensar, e não à capacidade de pensar", como afirma Denny (1995, p. 76), podemos constatar, com Olson (1995, p. 268), que "não há nenhum uso da escrita, por mais importante, que justifique estigmatizar como inferior metade da humanidade"4.

Barker e Escarpit (1975, p. 120) nos auxiliam nessa constatação quando evidenciam, com suas pesquisas, que "[...] não ler não significa a mesma coisa para um homem que vive em um mundo em que a leitura não tem lugar, nem objetivo, nem apoio permanente". Na mesma direção, os pesquisadores esclarecem um aspecto fundamental:

É claro que a leitura não pode ser "outorgada" como um favor: ela não pode ser implantada arbitrariamente em uma sociedade carente de estruturas de apoio ou de uma política sociocultural ampla capaz de fomentar o seu desenvolvimento. (BARKER; ESCARPIT, 1975, p. 134).

Isso significa que, para avançarmos em nossas reflexões sobre a apropriação da escrita em nosso país, é indispensável alterarmos modos de atuar, bem como de representar a cultura escrita, deixando para traz posições que tomam sua singularidade como modalidade cultural superior em si mesma, dando-se no interior de relações orientadas, implícita e/ou explicitamente, por

\footnotetext{
${ }^{3}$ Entre outros estudos, muitas dessas experiências estão reunidas em OLSON e TORRANCE (1995).

${ }^{4}$ As pesquisas de Olson referem-se a uma época em que os índices de analfabetos eram ainda maiores do que os atuais.
} 
ordens do conhecimento impositivas e fechadas à invenção, ao diálogo com a diferença e com o outro.

A partir da descrição de uma experiência pessoal, prosseguiremos com os argumentos nessa direção.

\section{A MEDIAÇÃO ESSENCIAL}

Quando eu era criança, me perguntavam se eu era paulista e respondia: "Médio". Nasci em São Paulo, mas toda a minha família, inclusive meus pais, são baianos. Cresci entre São Paulo e Salvador; morava na metrópole e passava as férias no litoral do Nordeste. As referências sociais e afetivas se complementavam entre amigos que dividiam comigo o cotidiano da adorada escola e a dezena de primos e tios que transbordavam carinho e brincadeiras nas intermináveis férias. E eu era "a paulista" entre os baianos e "a baiana" entre os paulistas. E eu me perguntava: falo muito rápido ou muito devagar? Digo "meu" ou "ôxi"? Meio paulista e meio baiana... Tão nordestina e tão paulistana. "O que é umbu?", perguntavam-me em São Paulo. Eu respondia com espanto por não conhecerem a fruta que não faltava na cozinha da minha "casa"... Que casa? Viver entre duas cidades e me sentir em casa- assim como em casas - sempre foi uma realidade para mim.

Em tempos sem internet e reduzidos recursos tecnológicos para a troca de informações e imagens (pelo menos se comparados aos dias de hoje), contar para os meus primos um filme que já havia estreado no Sudeste, assim como voltar para São Paulo sabendo de cor a "música do verão", para ensinar aos amigos, era um continuun entre "dois mundos" que, àquela época, pareciam distantes geográfica e culturalmente, mas tão integrados em mim. Fazia parte da minha vida essa hesitação de ser "entre"; crescendo a partir de dois lugares, sempre com um e com outro, às vezes mais um, às vezes mais outro; quando pudesse, um, quando quisesse, outro...

Assim como eu, tanta gente nasce e convive entre realidades diferentes - entre vocabulários, valores, ambientes, práticas sociais e culturais - e passam a vida combinando e confrontando modos de ser, saberes e fazeres em relação aos contextos nos quais vive e sobre os quais pensa. 
Até que chegou a adolescência. A crise com valores consumistas, o repúdio aos comportamentos "caretas", a insatisfação com a falta de diálogo e o desejo de falar e viver coisas novas. Eu também, como tantos outros adolescentes, procurava a minha identidade, o meu lugar em um mundo que parecia ao mesmo tempo incompleto e superlotado.

Tudo isso me afastou de casa (das casas) e me levou a procurar um intercâmbio, que, com esforço de meus pais e meu padrinho, permitiu-me passar doze meses na Dinamarca, mais especificamente em Tønder, uma cidade medieval de 8 mil habitantes, próximo da Alemanha.

Estranhamento total. Até chegar lá eu tinha visto poucas imagens do país, além de folders que fui buscar no consulado e algumas fotos da viagem de um amigo, que havia passado por Copenhague. Quando saí do aeroporto, já em terras escandinavas, todo o cenário era absolutamente novo. Engraçado lembrar hoje, como eu, com meus 17 anos à época, me senti como uma astronauta que chegava a Marte e era recebida por extraterrestres; lembro que perdi toda a minha espontaneidade quando vi os meus "pais de intercâmbio" e não sabia mais se devia cumprimentá-los com a mão estendida, com um abraço apertado, com um sinal de fumaça ou simplesmente sair correndo. Fui "salva" pelo instinto materno da minha "mãe dinamarquesa", que, assim que me localizou, agarrou-me contra seu peito em um abraço apertado e familiar.

Durante as primeiras semanas, tudo ainda tinha cara de novidade extraterrestre: desde a tonalidade constante azul-cinza-claro daqueles tantos olhos que me observavam - provavelmente com a mesma desconfiança, interesse e curiosidade com que os meus, castanhos, se dirigiam a eles - até as bicicletas por toda parte, a cidade de castelos, o nudismo na praia, as referências vikings...

Logo na primeira semana, recordo que fui de bicicleta para o centro e, na volta, fui emparedada pela viatura da polícia que fazia sinal para que eu parasse. Assustada, eu apenas repetia uma das únicas palavras que sabia até então na língua local: "Studenter, studenter". O policial só me pediu que acendesse o farol. Já era final da tarde e eu devia ligar a luz da bicicleta para poder circular. Penso até que meus "pais" devem ter me prevenido sobre isso, 
antes de eu sair, mas eram tantas as informações novas, que eu não devia reter nem a metade.

Lembro também que não demorou muito e fui levada à prefeitura da cidade onde, depois de apresentar o passaporte e os documentos de estudante estrangeira, recebi meus cartões de saúde, odontológico e... da biblioteca!

Até então, eu acho que nunca tinha ido a uma biblioteca pública. $\mathrm{Na}$ realidade, acho que nem mesmo havia pensado sobre sua existência. Nem a escola particular que eu havia estudado possuía uma. Eu lia bastante, na minha casa sempre teve muitos livros, revistas e jornais, mas eu não me lembro de ter conhecido esse local, esse ambiente coletivo e específico para os leitores.

A minha "mãe", auxiliar de laboratório no hospital da cidade, gostava de pegar emprestados semanalmente livros de literatura e de receitas. Meu "pai", operador de máquinas em uma gráfica - e "socialista", como se definia gostava de ler biografias de lideranças políticas humanistas. Minha "irmã", adolescente como eu, era uma devoradora de livros de todos os gêneros e usava a biblioteca também para estudar e encontrar os amigos.

Quando cheguei lá pela primeira vez, obviamente aquelas prateleiras repletas de textos numa língua estranha pouco me seduziram, mas, logo que adentrei a seção de literatura estrangeira, pude reconhecer alguns nomes como "Agatha Christie", "Milan Kundera" e até "Jorge Amado", com Capitães da Areia em inglês.

Minha "mãe" me apresentou à bibliotecária, uma senhora de cabelos grisalhos e pele bem enrugada, que me sorriu quando soube que eu vinha do Brasil. "Bem-vinda", me disse em um inglês carregado. E logo depois completou: "Achei que você viesse da Bósnia, como muitas outras moças que têm vindo, hospedadas em um abrigo da Cruz Vermelha, localizado aqui atrás". Era época de guerra e a Dinamarca havia acolhido refugiados, só em Tønder eram $800,10 \%$ da população local.

Eu nem sabia exatamente onde se localizava a Bósnia: "No, I'm Brazilian", acho que respondi. E percebi que naquele momento não fazia mais a menor diferença para ela - e para mim e para ninguém - se eu era baiana ou 
paulista, do Sudeste ou nordestina; eu me identificava agora completamente como "a brasileira", minha identidade era a de uma nação, uma pátria, uma língua...

Eu não esqueci mais aquele momento porque depois, durante os meses em que morei na cidade, voltei inúmeras vezes à biblioteca e, de fato, conheci muitas das moças bósnias que se empenhavam em aprender o dinamarquês para ali refazerem suas vidas. E eu, se me sentia inicialmente completamente diferente delas - eu era estudante, tinha uma "casa dinamarquesa", ia voltar para o meu país, enquanto elas eram bem mais velhas do que eu, andavam machucadas, com roupas doadas e pareciam distantes de qualquer "casa"... -, com o passar de algum tempo, fui me reconhecendo simplesmente "idêntica" a elas - cabelos e olhos tão escuros entre uma gente tão clara, um sorriso sem graça de quem não tem vocabulário suficiente para dizer mais do que "bom dia"; lendo livros infantis para nomear os termos correspondentes às figuras: "bola", "árvore" etc.

Uma identidade comum de "estrangeiras" parecia agora criar entre mim e aquelas moças bósnias uma afinidade surpreendente.

Eu sentia essa questão da identidade novamente. Não como algo estanque, mas a experiência que se move e se (re)define na relação com os outros e com os contextos nos quais nos vemos inseridos. E, ao mesmo tempo que se redefine, não exclui as anteriores, mas integra-as, transforma-as, renova-as.

Um dia, a bibliotecária se aproximou de mim e perguntou se eu gostaria de ler alto o livro que eu estava lendo, para ela poder me ajudar a acertar a pronúncia das palavras. Mesmo meio envergonhada, sentei ao lado de sua mesa e tentei falar em voz alta o som daquelas tantas consoantes consecutivas, da letra "o" partida ao meio, do "a" e "e" grudados... No final, achei divertidíssimo e lembro que naquela tarde voltei para casa saltitando pela calçada, como costumam fazer as meninas de 5 anos.

Dias depois, retornei à biblioteca e novamente escolhi um livro. A bibliotecária sorriu para mim e fez o sinal com as mãos que eu entendi como 
"mais tarde poderemos repetir, se quiser". Eu confirmei com um sorriso e um "o.k.", e fiquei ensaiando sozinha até a hora de ler alto.

Nisso, eu vi que chegavam ali também duas moças bósnias e que foram ler jornais. Fiquei observando como elas, sortudas, podiam ao menos se comunicar entre si na língua materna... Davam risadas, faziam caretas, conversavam muito.

Quando a bibliotecária me convidou, com as mãos, para me sentar ao seu lado, me levantei e apontei discretamente para as duas moças, perguntando: "O que você acha de convidá-las também?". A bibliotecária fez um "não" com a cabeça e me chamou para sentar.

"The noise", "o barulho", ela me disse baixinho. "Se estivermos em grupo vai fazer muito barulho aqui". "O.k.", eu entendi e parti para minha "chamada oral".

Qual foi minha surpresa quando, em outro dia, volto à biblioteca e a dinamarquesa me conduz a uma sala menor, que eu não conhecia, dentro da biblioteca, onde já estavam outras três moças refugiadas da guerra. "Aqui podemos fazer bastante noise", ela sorriu.

$\mathrm{E}$, durante meses, passei a ir para aquela sala pelo menos uma vez por semana, ler literatura infantil dinamarquesa com as moças bósnias e a senhora bibliotecária.

Lembro que a bibliotecária resolveu ler Capitães da Areia e comentava eventualmente comigo os cenários e personagens baianos, que eu podia reconhecer tão bem. Do mesmo modo, ela passou a guardar os artigos de jornais que saíam sobre a guerra e entregava às minhas colegas, que levavam para o abrigo as notícias mais recentes.

Hoje em dia, eu não me recordo de nenhum dos textos que lemos juntas; tenho no máximo a lembrança vaga de algumas ilustrações coloridas e de nossas risadas. E também não lembro se avançamos muito na língua, porque recordo que a bibliotecária dizia sorridente que todas nós tínhamos uma "pronúncia péssima" ("It's ugly?"). Mas o fato é que essa experiência me marcou profundamente. 
Quando voltei ao Brasil, escolhi fazer Ciências Sociais, principalmente, levada pela curiosidade por disciplinas como a Antropologia - e sua busca efetiva pela compreensão dos sentidos do outro. E mais tarde passei a trabalhar em projetos de implantação de bibliotecas e formação de leitores.

Hoje, percebo como essa experiência na biblioteca dinamarquesa pode ter sido essencial para essas minhas opções. Observo também como não foi um gesto qualquer aquele no qual ela me propôs as leituras em voz alta, depois, ao negar inicialmente a participação das moças bósnias, para, por fim, propor outro ambiente onde pudéssemos nos reunir.

A bibliotecária não se revelou prisioneira de uma ordem cultural preestabelecida, que não permitia que fossem modificados quaisquer dos comportamentos "esperados" de um leitor e de um ambiente como o da biblioteca. Ao contrário, a bibliotecária mostrou-se atenta e aberta ao que buscavam os frequentadores do espaço naquele momento e, em um processo implícito de negociação com a ordem estabelecida de seu trabalho, com os outros usuários e comigo, promoveu um ambiente novo, gerador de novas relações entre nós, os textos, a própria biblioteca e a bibliotecária.

Essa negociação foi, a meu ver, experiência crucial para a efetivação de outra que acabou por influenciar os rumos de minha vida pessoal e profissional: passamos de usuários, coadjuvantes em uma cultura escrita que estaria pronta, definida, estabelecida em seus sentidos e práticas, para nova condição: aquela na qual éramos protagonistas, criadores de sentidos para nós mesmos, dos textos e contextos de que participávamos.

\section{A BUSCA PELA EXPERIÊNCIA ESSENCIAL: A NEGOCIAÇÃO}

Desde 1999, trabalho em organizações governamentais como mediadora de leitura, procurando criar situações de encontros prazerosos entre as pessoas e os livros de literatura, sem as exigências de apreensão obrigatória de conteúdos predeterminados, de alfabetização e avaliação que, com frequência, marcam a trajetória com os livros.

A experiência profissional no campo da mediação de leitura me dizia que as ações e concepções implicadas nessa prática atrelavam-se principalmente à 
ideia de que mediar é transmitir algo para o outro, construindo pontes entre as pessoas e algo ou alguém que Ihe é estranho: eu, no caso, atuava fazendo a mediação entre jovens, professores, educadores sociais, estudantes e a literatura, procurando transmitir o prazer que a leitura de um texto poderia proporcionar, a sensação de quanto uma biblioteca poderia ser aconchegante etc.

Até que a experiência de implantar e acompanhar um projeto de leitura na zona rural, durante sete anos, colocou em xeque essa concepção: depareime com a resistência dos adultos daquela fazenda entrarem no Centro Cultural recém-criado para eles e participarem das atividades propostas. Enquanto as crianças e os jovens passavam horas de seus dias conosco, os adultos, mesmo em períodos de folga, preferiam reunir-se na frente das suas casas ou na beira do fogão à lenha - e nunca no Centro Cultural, que se oferecia defronte às casas.

"Isso é bom para as nossas crianças aprenderem, mas eu não tenho nada para fazer lá", era uma resposta comum entre os adultos quando questionados sobre sua frequência no espaço.

Observávamos que, se o "prazer de ler e ouvir livros de literatura" era algo que gostaríamos de transmitir para aquela população, havia entre essa prática e os adultos do Centro Cultural a fratura histórica entre os letrados e não letrados no Brasil: "eu não tenho nada para fazer lá" revelava, mais do que desinteresse, a descontinuidade entre as experiências culturais, refletida também no depoimento de Marciel, 12 anos, que dizia: "A minha mãe não vem aqui porque ela não estudou, acho que ela tem vergonha".

Dona Ana, senhora de 65 anos, mãe de seis filhos confirmava: "Eu não vou não, eu não vou saber fazer nada".

Por que uma pessoa que não pertence à cultura escrita sente-se ignorante - e mesmo impotente - diante da cultura escrita, como se não soubesse "nada"? Por outro lado, para aqueles que vêm de meios não letrados, por que a entrada na cultura escrita tem que se transformar, como mostrou Hoggart (1977), em uma ruptura do sujeito com seus meios de origem, seus outros modos de agir, aprender, se expressar. Por que ruptura e não 
A bibliotecária dinamarquesa e a negociação cultural: novo paradigma para a mediação e apropriação da informação

construção, transformação, renovação - tanto dos sujeitos, como da própria cultura escrita e seus contextos e relações?

A partir da minha dissertação de mestrado, defendida em 2009, pude, com a orientação do Professor Edmir Perrotti, começar a identificar elementos conceituais que estavam implicados nesses questionamentos: como uma prática cultural nova (no caso, da leitura literária) pode engendrar práticas mais antigas e orgânicas, no caso, dos moradores da Fazenda? Procurei aprofundar as discussões sobre dispositivos dialógicos de mediação cultural (FOUCAULT, 1984; PIERUCCINI, 2004) visando à sua apropriação (CHARTIER, DEL PRIORI, 1999; CERTEAU, 1994; SERFATY-GARZON, 2003) e não simplesmente à sua "assimilação" pelos diferentes públicos.

A continuidade dos trabalhos de pesquisa e como mediadora de leitura me levou, em 2010, à busca pelo doutorado e a Paraisópolis, segunda maior favela de São Paulo, quando passei a coordenar um grupo de adolescentes mediadores de leitura. Os jovens, entre 14 e 17 anos, frequentavam um projeto social do bairro no qual havia uma biblioteca e onde passei a encontrá-los semanalmente durante quatro meses. E, mais uma vez, reconhecia a distância entre as práticas exigidas na cultura letrada e as outras experiências culturais significativas para os sujeitos: os adolescentes desse grupo em Paraisópolis, todos filhos de imigrantes nordestinos, não conheciam, por exemplo, o nome das cidades de origem de seus pais - a maioria sabia dizer no máximo o Estado - e afirmavam que não gostavam da escola porque "é chata", "porque a gente não pode fazer nada", "porque tem que ficar sentado ali o dia inteiro".

\footnotetext{
${ }^{5}$ Estudo sobre a apropriação da leitura como negociação de sentidos, defendida pela autora no Programa de Pós-Graduação em Ciência da Informação da ECA-USP (2009), realizada com apoio da CAPES (2007-2009). (OLIVEIRA, 2009). Dois artigos decorrentes da dissertação de mestrado, apresentados e premiados em eventos científicos no Brasil, já indicavam a preocupação com a questão da leitura como negociação: "Menção honrosa" no Seminário Internacional Sobre História do Ensino de Leitura e Escrita (UNESP, Marília), com o texto intitulado: "A apropriação da cultura escrita como experiência de negociação de sentidos em um contexto rural de Minas Gerais". UNESP, Marília, 2010; "Melhor trabalho" no XII Encontro Nacional de Pesquisa em Ciência da Informação (Grupo de Trabalho Mediação, Circulação e Apropriação da Informação) com a apresentação do artigo intitulado: "A mediação da informação como experiência de negociação de sentidos". ANCIB, Brasília, outubro de 2011.
} 

mediação e apropriação da informação

Eu, novamente, observava a entrada na cultura escrita como experiência fragmentada da vida cotidiana e da memória cultural dos sujeitos e mais, experiência que impõe, além de acesso a bens culturais determinados, também habilidades, competências, atitudes, concepções e valores ligados a grupos específicos e socialmente hegemônicos, sem considerar outros sujeitos e outras modalidades culturais.

Retomo agora a situação vivida com a bibliotecária dinamarquesa e me pergunto: quem são esses sujeitos que adentram uma biblioteca, oriundos de "outro mundo" - onde não se gosta de ler, ou não se sabe ler? Por outro lado, como se sentem ao adentrarem o "mundo dos livros" sem encontrar ali quaisquer referências de suas origens, de seus pais, de seu "país"? Adentrar a cultura letrada significaria a salvação da ignorância para eles? Eu pensava em mim mesma como esse "outro" na Dinamarca - "terceiro-mundista", "ignorante", "subdesenvolvida"? Não foi desse modo que fui reconhecida. E nem as moças bósnias. Talvez, se fôssemos tratadas dessa maneira, nunca mais voltássemos para aquela biblioteca.

Existe, assim - essa é nossa hipótese -, uma diferença crucial entre difundir "promover" a cultura escrita, no sentido de incluir populações afastadas dessa modalidade para que passem a fazer parte do circuito "consagrado", e criar condições de interlocuções diversas entre diferentes leitores e leituras, entre realidades sociais, culturais e pessoais diversas e dinâmicas.

O que significa ser o "caipira", o "jovem", o "da periferia", o "imigrante"? "Leitor", "não leitor"? O que significa estar excluído (ou incluído) da "cultura escrita"? Dessa maneira, partimos do pressuposto de que é determinante o como e com quais características se enuncia o outro, como construímos nossa identidade e alteridade, como define e é definida a ordem histórica que nos coloca em relação a nós mesmos e ao outro.

Ao enfrentar conflitos provocados pela divergência e/ou assimetrias entre os diferentes grupos socioculturais nas nossas sociedades, o conceito de "negociação cultural" poderá se mostrar capaz de favorecer a construção de projetos culturais orientados em direção à construção de uma sociedade 
democrática, plural, humana, que articule políticas de direitos à apropriação cultural.

Se desde a Antiguidade, a escrita foi objeto ou de controle ou de disseminação visando à regulação social via assimilação da cultura do outro, nossa proposta vai em outra direção, ou seja, da apropriação, do protagonismo e do direito à participação afirmativa na cultura.

\section{REFERÊNCIAS}

BARKER, R.; ESCARPIT, R. A fome de ler. Rio de Janeiro: FGV, 1975.

CERTEAU, M. A invenção do cotidiano: artes do fazer. Rio de Janeiro: Vozes, 1994.

CHARTIER. R. Textes, imprimés, lectures. Pour une sociologie de la et lecteurs. dans la France contemporaine, Cercle de la librairie, Paris: La trasposición didáctica; Buenos Aires: Aique, 1988.

CHARTIER R.e M. DEL PRIORI. A ordem dos livros: leitores, autores e bibliotecas na Europa entre os séculos XIV e XVIII. Brasília: UnB, 1999.

DENNY, J. P. O Pensamento racional na cultura oral e a descontextualização da cultura escrita. In: OLSON, D.; TORRANCE, N. Cultura Escrita e Oralidade. São Paulo: Ática, 1995.

FOUCAULT, M. Vigiar e Punir. Petrópolis: Vozes, 1984.

FREIRE. P. A importância do ato de ler: em três artigos que se completam. São Paulo: Cortez, 1982.

Ação cultural para a liberdade. Rio de Janeiro: Paz e Terra. 1981a.

Extensão ou comunicação. 7. ed. Rio de Janeiro: Paz e Terra, 1983.

Pedagogia do oprimido. Rio de Janeiro: Paz e Terra, 1981b.

HOGGART, R. The uses of literacy: aspects of working-class life with special reference to publications and entertainments. London: Chatto and Windus, 1977.

INSTITUTO PAULO MONTENEGRO; AÇÃO EDUCATIVA. INAF Brasil 2011: Indicador de Analfabetismo funcional - principais resultados. Disponível em: http://www.ipm.org.br/ptbr/programas/inaf/relatoriosinafbrasil/Paginas/inaf2011 2012.aspx. Acesso em 05 de julho de 2016. 
INSTITUTO PRÓ-LIVRO. Retratos da leitura no Brasil: realização. 3. ed. São Paulo: Ibope Inteligência, [2011]. Disponível em: < http://prolivro.org.br/home/images/relatorios boletins/3 ed pesquisa retratos leitura I

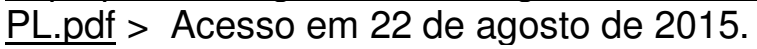

LÉVI-STRAUSS. C. Tristes trópicos. São Paulo: Companhia das Letras, 1996.

MANGUEL. A. Uma história da leitura. São Paulo: Companhia das Letras, 1996.

OLIVEIRA, A. L. Cultura na fazenda: um estudo sobre a apropriação da leitura como negociação de sentidos. 2009. Dissertação (Mestrado em Ciência da Informação) ECA/USP, São Paulo, 2009.

OLSON, D.; TORRANCE, N. Cultura escrita e oralidade. São Paulo: Ática, 1995.

PERROTTI, E. e I. PIERUCCINI. Infoeducação: saberes e fazeres da contemporaneidade. In: M.L.G LARA, A. FUJINO e D. P. NORONHA (Org.). Informação e contemporaneidade: perspectivas. Recife: Néctar, 2007. p.4697. Disponível em:< http://www2.eca.usp.br/nucleos/colabori/documentos/Infoeducacao.pdf> . Acesso em: 10 de julho de 2016.

PETIT. M. Os jovens e a leitura: uma nova perspectiva. São Paulo: Ed. 34, 2008.

PIERUCCINI, I. A ordem informacional dialógica: estudo sobre a busca de informação em educação. 2004. 194 f. Tese (Doutorado em Ciência da Informação) Escola de Comunicações e Artes, Universidade de São Paulo, São Paulo. Disponível em:< http://www.teses.usp.br/teses/disponiveis/27/27143/tde-14032005-144512/ptbr.php $>$ Acesso em 10 de julho de 2016.

SERFATY-GARZON, P. Dictionnaire critique de I'habitation et du logement. Paris: Armand Colin, 2003. p. 27-30.

UNESCO. Adult and youth literacy national, regional and global trends, 19852015. Disponível em: $<$ http://www.uis.unesco.org/Education/Documents/literacy-statistics-trends1985-2015.pdf. >. Acesso em 05 de julho de 2016.

Title

The Danish librarian and cultural negotiation: new paradigm for mediation and appropriation of information

\section{Abstract:}

Introduction: It presents results of doctoral thesis.

Objective: This article aims to contribute to the definition and development of the concept "cultural negotiation", understood as a theoretical-methodological category guiding the mediation processes used to suit the written culture.

Methodology: Collaborative methodology has been used, in other words, a scientific construction process based on the dialogue between scientific knowledge and "action", adopting, however, a perspective that does not reduce or overlap one another. 
Results: The results indicate that by acknowledging and incorporating their concepts and processes, the conflicts caused by divergences and/or asymmetries between the different individuals, groups, segments, categories, sociocultural matrix (readers/nonreaders, oral tradition/written culture), the case shown (a Danish public library), unlike others of the same content are, rather than instances of control and/or dissemination, it's instance of cultural negotiation involving subjects, texts and contexts in active, assertive and complex processes of information and cultural appropriation, including - but not exclusively - written culture.

Conclusions: The concept of cultural negotiation, therefore, points out to new perspectives concerning written culture, as well as cultural appropriation as a whole. Simultaneously, it indicates to be able to contribute to redefine essential practices and concepts of cultural mediation and its paradigms.

Keywords: Mediation. Cultural negotiation. Cultural appropriation. Library. Writing culture.

\section{Titulo}

Apresentar o título em espanhol (para textos em português e inglês).

\section{Resumen:}

Introducción: Presenta resultados de la tesis de doctorado.

Objetivo: Su objetivo es contribuir a la definición y el desarrollo del concepto de "negociación cultural", entendida como categoría teórica-metodológica fundamental para los procesos de mediación encaminadas a la apropiación de la información.

Metodología: Se utilizó la metodología de colaboración, proceso de construcción científica basada en el diálogo entre el conocimiento y las prácticas científicas y "acción", la adopción, sin embargo, una perspectiva que no reduzca o se superponen entre sí.

Resultados: Los resultados muestran que, al reconocer e incorporar sus conceptos y procesos conflictos causados por las diferencias y / o asimetrías entre los diferentes individuos, grupos, categorías, segmentos, matrices socioculturales (lectores / los no lectores, tradición oral / cultura de la escritura ), el dispositivo que se muestra (biblioteca pública en Dinamarca), a diferencia de otros del mismo contenido, en lugar de las instancias de control y / o de difusión, son instancias de negociación cultural, con la participación de los sujetos, textos y contextos en los procesos activos, complejos y asertivo de apropiación de la información y la cultura, incluido allí - pero no exclusivamente - la cultura escrita.

Conclusiones: El concepto de puntos de negociación cultural, por lo tanto, a nuevas perspectivas, tanto en relación con la apropiación de la cultura escrita, y la cultura en general. Da programas al mismo tiempo, para contribuir a la necesaria redefinición de las prácticas y conceptos de información de mediación y sus paradigmas.

Palabras clave: La mediación; Negociación cultural; Propiedad; Biblioteca; Cultura escrita.

Recebido em: 25.08.2016

Aceito em: 30.11.2016 